Behavioural Brain Research Special Edition: Functions of Rodent Prefrontal Cortex

Guest Editor: Bryan Kolb

\title{
What the rodent prefrontal cortex can teach us about attention-deficit/hyperactivity disorder: The critical role of early developmental events on prefrontal function.
}

Ron M. Sullivan ${ }^{1}$ and Wayne G. Brake ${ }^{2}$

\author{
${ }^{1}$ Centre de Recherche Fernand-Seguin \\ Dept. of Psychiatry \\ University of Montreal \\ ${ }^{2}$ Laboratory for Neurodevelopment \\ Dept. of Psychology and Neuroscience Research Institute \\ University of California, Santa Barbara
}

Text Pages: 28

Figures: 1

\section{Corresponding Author:}

Wayne G. Brake, Ph.D.

Department of Psychology

University of California Santa Barbara

Santa Barbara, CA, 93101-9660

Phone: (805) 893-5006

FAX: (805) 893-4303

E-mail: brake@psych.ucsb.edu 
Full address of all authors:

\author{
Ron M. Sullivan \\ Dept. of Psychiatry \\ University of Montreal \\ Centre de Recherche Fernand-Seguin \\ 7331 rue Hochelaga \\ Phone: (514) 251-4015 Ext. 3553 \\ FAX: (514) 251-2617 \\ E-mail: rsullivan@ crfs.umontreal.ca
}

\author{
Wayne G. Brake \\ Department of Psychology \\ University of California, Santa Barbara \\ Santa Barbara, CA, 93101-9660 \\ Phone: (805) 893-5006 \\ FAX: (805) 893-4303 \\ E-mail: brake@psych.ucsb.edu
}


Abstract The present review surveys a broad range of findings on the functions of the rodent prefrontal cortex (PFC) in the context of the known pathophysiology of attentiondeficit/hyperactivity disorder (ADHD). An overview of clinical findings concludes that dysfunction of the right PFC plays a critical role in ADHD and that a number of early developmental factors conspire to increase the risk of the disorder. Rodent studies are described which go far in explaining how the core processes which are deficient in ADHD are mediated by the PFC and that the mesocortical dopamine (DA) system plays a central role in modulating these functions. These studies also demonstrate a surprising degree of cerebral lateralization of prefrontal function in the rat. Importantly, the PFC is highly vulnerable to a wide variety of early developmental insults, which parallel the known risk factors for ADHD. It is suggested that the regulation of physiological and behavioral arousal is a fundamental role of the PFC, upon which many "higher" prefrontal functions are dependent or at least influenced. These right hemispheric arousal systems, of which the mesocortical DA system is a component, are greatly affected by early adverse events, both peri- and post-natally. Abnormal development, particularly of the right PFC and its DAergic afferents, is suggested to contribute directly to the core deficits of ADHD through dysregulation of the right frontostriatal system.

\section{Keywords:}

arousal

dopamine executive function

maternal separation stress

anoxia emotional regulation asymmetry 


\section{Introduction}

The neurodevelopmental disorder known as attention-deficit/hyperactivity disorder or ADHD, is the most prominent childhood psychiatric condition and its features or core deficits frequently persist well into adulthood. It is increasingly appreciated that functional deficits in frontostriatal circuitry contribute substantially to the pathophysiology of ADHD and that the right prefrontal cortex (PFC) is especially important in this regard. While genetics play a very important role in this condition, intra-uterine, perinatal and postnatal factors have all been significantly linked with the development of ADHD.

Studies in the rodent have revealed that the PFC is intimately involved in mediating numerous neural functions of central relevance to ADHD, not only behavioral inhibition, attentional processes and working memory, but also less appreciated aspects of this condition such as arousal level, physiological stress responsiveness and emotional self-regulation. Not surprisingly, the maturation of these prefrontal circuits is significantly affected by a wide variety of early developmental events, both adverse and advantageous. The present review examines many of these animal findings and describes the important modulatory role of mesocortical dopamine (DA) on PFC function, as well as the extent to which this system may be particularly vulnerable to early developmental insults. Many of these findings also highlight the important role of cerebral laterality in mediating the above processes, even at the level of the rodent.

The first section of the paper thus provides a brief overview of the pathophysiology of ADHD with particular reference to PFC dysfunction and the proposed nature of altered DA function in this condition. The following sections review the rodent literature in terms of how the PFC modulates the various processes deemed central to ADHD symptomology. The final 
sections discuss first the evidence that early adverse events contribute to the development of ADHD, and secondly, that in rodents numerous early manipulations modeled upon these types of events lead to long-lasting impairments in prefrontal function. It is proposed that early adverse events impact negatively on the maturation of prefrontal circuits particularly in the right hemisphere, and that deficits in mesocortical DA function in this region contribute significantly to ADHD symptomology.

\section{Prefrontal Involvement in ADHD Pathophysiology and the Possible Role of DA}

Numerous reviews have elucidated the behavioral and cognitive characteristics of ADHD in great detail, as well as describing the known neuropathological correlates of this condition (eg. Barkley, 1997, 1998; Castellanos, 1997; Castellanos and Tannock, 2002; Spencer et al., 2002; Swanson et al., 1998). The present paper focuses on the pivotal role that the PFC appears to play in mediating the spectrum of ADHD symptomology.

Heilman et al. (1991) proposed that the pathophysiology of ADHD derives from rightsided frontal-striatal dysfunction in combination with an impairment of the mesocortical DA system. Since this time, brain imaging studies have done much to support this view. Numerous structural imaging studies have reported significantly reduced volume of the right frontal (particularly prefrontal) cortex in ADHD subjects (Castellanos et al., 1996b; Filipek et al., 1997; Casey et al., 1997; Pueyo et al., 2000; Mostofsky et al., 2002) in conjunction with right caudate abnormalities. Casey et al. (1997) reported that such right frontal volume reductions are significantly correlated with impaired performance in response inhibition tasks. Neuropsychological and other studies have support the view that ADHD is a disorder of right hemispheric function, primarily right-sided attentional and arousal systems (Voeller and 
Heilman , 1988; Carter et al., 1995; Malone et al., 1988; Campbell et al., 1996; Stefanatos and Wasserstein, 2001). For example, Silberstein et al. (1998) employed an electrical brain mapping technique during a continuous performance task to demonstrate that normal boys show an increased speed of processing during critical periods of the task, specific to right prefrontal sites. However, this task-related change in processing ability was not evident in ADHD boys. Moreover, functional imaging studies have shown that a normal right prefrontal increase in metabolism during response inhibition tasks, is markedly reduced in ADHD subjects (Langleben et al., 2001; Rubia et al., 1999; 2001).

Abnormalities in DAergic transmission are well accepted as predisposing factors in ADHD, yet the nature of DAergic dysfunction is not well understood. Given the strong genetic component in the incidence of ADHD, it is notable that at least four DA-related gene loci have been implicated in this condition, including that of the DA transporter or DAT (Cook et al., 1995; Gill et al., 1997; Kirley et al., 2002; Hawi et al., 2003). While no single gene abnormality reliably predicts the occurrence of $\mathrm{ADHD}$, it is quite possible that one or more DA-related gene variants contribute to the abnormal development and functioning of certain DA circuits, thus predisposing to the development of the disorder.

The most common treatment for ADHD is methylphenidate or Ritalin, which blocks DA reuptake into the cell by the DAT. The resulting elevations in synaptic DA levels are presumed to be related to its therapeutic benefits at some level, but the most critical site(s) of action for these effects is the subject of debate. Perhaps the most parsimonious theory accounting for DA involvement in ADHD was put forward by Castellanos (1997), who proposed that a mesocortical DA deficit (related to attentional and executive deficits) coexists with a striatal hyperDAergic state (related to behavioral hyperactivity, Castellanos et al., 
1996a). As such, enhancing prefrontal DA activity would have the greater therapeutic benefit. This theory also proposed (based on regional differences in DA autoregulation) that continued treatment with methylphenidate would result in a constant facilitation of PFC DA function, but would lead to a downregulation of striatal DA function. Recent findings by Ernst et al., (1998) suggest prefrontal DAergic deficits in ADHD. In a PET study measuring the uptake of $\left[\mathrm{F}^{18}\right]$ fluorodopa to assess DOPA decarboxylase activity (and thus DA synthesis), it was found that $\left[\mathrm{F}^{18}\right]$-DOPA uptake ratios in medial PFC were reduced by approximately half in ADHD subjects compared to controls, with no such effect seen in striatum.

Additional neuropharmacological evidence reinforces the importance of the PFC in providing therapeutic benefits in ADHD. The selective norepinephrine uptake inhibitor atomoxetine, has been shown in clinical trials to be at least as effective as methylphenidate in the treatment of ADHD (Kratochvil et al., 2002). In the rat, elevations of norepinephrine in PFC following atomoxetine, independently increase local DA levels as well (Gresch et al., 1995). While methylphenidate increases extracellular levels of DA 3-fold in both PFC and striatum, atomoxetine also increases DA levels 3-fold in PFC, but has no effects in striatum (Bymaster et al., 2002). Such findings strongly support the notion that the PFC is the more crucial site in the amelioration of ADHD symptoms. Moreover, facilitating PFC DA activity, and possibly that of norepinephrine as well, may contribute in large part to the therapeutic effects of such drugs. 


\section{Rodent Studies of PFC Function of Relevance to ADHD}

\subsection{Prefrontal regulation of subcortical DA systems}

It is well known that the frontal cortex projects massively to basal ganglia as part of a series of feedback loops, to regulate a broad spectrum of functions from executive to motor to affective (Alexander et al., 1986). It is thus not surprising that frontostriatal circuits are implicated in a number of forms of psychopathology. In the case of ADHD, as stated above, a prefrontal DA deficit is suggested to coexist with excessive striatal DAergic function. There are numerous findings in the rodent literature, which not only suggest that these two conditions can coexist, but that a PFC DA deficit can directly induce an upregulation of striatal DA activity.

Depletion of medial prefrontal DA with 6-hydroxydopamine (6-OHDA) has been shown to increase DA turnover in basal ganglia structures (Pycock et al., 1980). It has also been reported that DA depletion of the right PFC alone, but not the left, results in bilateral increases in striatal DA turnover ratios, at least following exposure to stress (Sullivan and Szechtman, 1995). Other studies report that increased DA activity in dorsal or ventral striatum following prefrontal DA depletion or receptor blockade, is particularly evident after pharmacological challenge, exposure to mild stress or exposure to positively reinforcing

stimuli (Deutch et al., 1990; Mitchell and Gratton, 1992; Rosin et al., 1992; Banks and Gratton, 1995; Doherty and Gratton, 1996). The reciprocal relationship between prefrontal and subcortical DA systems is also shown by the fact that injection of the DA agonist apomorphine into medial PFC reduces DA metabolism in the caudate nucleus (Jaskiw et al., 1991). This 
reciprocal relationship between DA systems is also reflected behaviorally in the expression of locomotor activity.

\subsection{Regulation of motor activity by prefrontal cortex}

Rodent studies have demonstrated a specific role for mesocortical DA in motor inhibition. While the systemic or subcortical administration of DAergic agonists or DAreleasing agents can greatly increase motor activity, the intracortical administration of such drugs counteracts this activation. For example, amphetamine injected directly into the medial PFC, blocks the locomotor-activating effects of amphetamine injected into the ventral striatum (Vezina et al., 1991). Conversely, the same study reported that intracortical injection of DA D1 receptor antagonists enhances the activating effects of subcortical amphetamine, while drugs more selective for other DA receptor subtypes or noradrenergic and serotonergic receptors were ineffective in altering motor behavior. In another study, the DA agonist quinpirole, when injected into the medial PFC, completely blocked the motor activating effects of acute, peripherally administered cocaine (Beyer and Steketee, 2000). In contrast, DA depletion of the medial PFC with 6-OHDA increases both the locomotor activating effects and the subcortical DA release, induced by the peripheral administration of either amphetamine or cocaine (Banks and Gratton, 1995; Beyer and Steketee, 1999).

Rodent studies have also shown that the right frontal cortex is especially important in motor inhibition. A variety of lesion techniques including 6-OHDA lesions, of right but not left frontal cortex, results in pronounced behavioral hyperactivity and altered subcortical catecholamine function (Robinson, 1979; Robinson and Stitt, 1981; Pearlson and Robinson, 1981; Kubos et al., 1982). Such findings are also in keeping with recent human imaging data. 
For instance, when subjects were required to withhold a learned motor response, structures which were strongly activated included middle and inferior frontal gyri and frontal limbic cortex. Moreover, this activation was strongly lateralized to the right hemisphere (Garavan et al., 1999).

It thus appears that right frontal systems play a key role in motor inhibition and that mesocortical DA is an important part of this regulation. Any conditions involving compromised development or functioning of this system would therefore be expected to exhibit varying degrees of behavioral hyperactivity.

\subsection{Regulation of executive functions by prefrontal cortex}

Perhaps the best known role of the prefrontal cortex concerns the realm of "executive" functioning, namely the intimately associated processes involved in decision-making, attentional control and working memory. Indeed, deficits in these areas are a defining feature of ADHD, whether hyperactivity is present or not (eg. Barkley, 1997; 1998; Schweitzer et al., 2000).

An integral aspect of attentional control and working memory (which allows for optimal decision-making), is the ability to hold relevant information "on line" for brief periods. Much of our knowledge of prefrontal regulation of executive function comes from the excellent work in primates employing delayed response tasks, where electrophysiological studies have demonstrated that classes of PFC neurons fire specifically during the delay period between presentation of a task-relevant stimulus and performance of the required response. Importantly, the activity of such neurons is precisely regulated by mesocortical DA, as either too much or too little DA D1 receptor stimulation alters the firing pattern of these neurons and 
impairs task performance (Sawaguchi and Goldman-Rakic, 1991; Williams and Goldman, 1995; Murphy et al., 1996; Sawaguchi, 2001).

In the rodent, possibly the best means of studying attentional control over performance, involves a behavioral paradigm known as the 5-choice serial reaction time task (or 5CSRTT), which can measure aspects of sustained attention, or selective and divided attention (for review, see Robbins, 2002). With this task, low doses of methylphenidate have been shown to reduce premature or impulsive responding and also tend to improve accuracy of responding in poorly performing animals (Puumala et al., 1996). When DAergic drugs are injected directly into the medial PFC, task performance is significantly affected in a manner dependent on individual differences in baseline task performance. Intracortical D1 agonists significantly enhance performance accuracy in rats with low baseline performance, but not in rats already performing at a high or optimal level (Granon et al., 2000). Conversely, local D1 receptor blockade impairs choice accuracy, but only in rats already performing at a high level. IntraPFC administration of D1 agonists has also been shown to improve memory retrieval in a delayed version of the radial maze task, but only after long delays (Floresco and Phillips, 2001).

Rodent studies employing the 5CSRTT have even reported hemispheric differences in the regulation of task performance. For example, post mortem measures of DA turnover ratios (DOPAC/DA) in the right but not left PFC, showed significant positive correlations with choice accuracy, while serotonin turnover in the right PFC was related to premature or impulsive responding (Puumala and Sirvio, 1998).

In general, the role of mesocortical DA in attentional processes has thus been described as making the animal focus more effectively on the stimuli currently controlling performance, 
reflected in performance improvements seen following D1 stimulation in the 5CSRTT requiring divided and shifting attention (Robbins, 2000). It is noteworthy that ADHD children are particularly impaired in the ability to relocate their attention focus, and to disengage attention rapidly from one spatial location to another, due to compromised right hemisphere attention systems (McDonald et al., 1999). Such executive functions are known to be improved in humans by DA receptor agonists (Muller et al., 1998), and methylphenidate induces similar effects in both normal adults (Mehta et al., 2000) and in children with ADHD (Kempton et al., 1999).

Taken together, the animal studies demonstrate a very important role for mesocortical DA in the modulation of executive functions and suggest that a critical window of DA activity is necessary for optimal cognitive functioning. Indeed, it is reminiscent of the classic inverted U relationship, or Yerkes-Dodsen Law, between arousal and performance, as too much or too little cortical DA is detrimental to performance. A major factor in determining the amount of cortical DA activity is stress, either acutely or chronically, as the mesocortical DA system is especially responsive to even acute, mild stressors. Chronic stress in rats has been shown to reduce PFC DA transmission in association with impairments in working memory; impairments which are ameliorated by intra-PFC infusion of D1 receptor agonists (Mizoguchi et $a l ., 2000)$. It is therefore likely that individual differences in physiological arousal and the ability to respond to stress, could account in significant part for variations in executive functions mediated by the PFC. 


\subsection{Regulation of physiological arousal, stress responsivity and emotional behavior}

In humans, the right hemisphere is believed to contribute to the arousal dimension of attention, and ADHD, by virtue of right hemispheric dysfunction, has been described as a hypovigilant state (Weinberg and Harper, 1993). Not only are deficits in arousal level and emotional self-regulation well recognized in ADHD (Barkley, 1997; 1998), but numerous studies of ADHD subjects have shown significantly impaired functioning of the stress regulatory systems so closely linked with emotion and arousal. Autonomic hypoarousal has been demonstrated in ADHD adolescents both at rest and during attention-demanding tasks (Lazzaro et al., 1999; Beauchaine et al., 2001). Failure to make normal cardiac adjustments in such tasks, was suggested to result from deficient cortical control over relevant visceral efferents (Althaus et al., 1999). Neuroendocrine functioning is also impaired in ADHD subjects, as reflected in the loss of normal diurnal cortisol rhythms (Kaneko et al., 1993) and lower salivary cortisol levels following performance of attention-demanding tasks, particularly in subjects with the most pronounced symptoms (Kariyawasam et al., 2002; King et al., 1998).

In the rodent, many studies have described the role(s) of the medial PFC in regulating autonomic, neuroendocrine and emotional states, and in cases where hemispheric differences have been examined, the right PFC appears to be especially important in this regard. The ventromedial PFC (particularly infralimbic cortex) is regarded as a visceromotor output station, which interacts closely with orbitofrontal networks and receives abundant stress and emotionrelated inputs from subcortical and/or limbic structures (Price, 1999; Cechetto and Saper, 1990). In turn, ventromedial PFC efferents modulate many subcortical and brainstem sites controlling autonomic and neuroendocrine activation and emotional expression (Hurley et 
al.,1991; Takagishi and Chiba,1991; Terreberry and Neafsey,1987; Jodo et al.,1998, Sesack et al., 1989; Bacon and Smith, 1993).

The autonomic effects of prefrontal manipulations in rodents and other species have been reviewed elsewhere (eg. Cechetto and Saper, 1990; Van Eden and Buijs, 2000). The ventromedial PFC appears necessary for full sympathetic activation in times of stress, as lesions in this area alter the respiratory and cardiovascular changes associated with conditional emotional responses (Frysztak and Neafsey, 1991; 1994). Stimulation of this area elicits sympathetic responses, while more dorsal PFC stimulation tends to produce parasympathetic profiles (Powell et al., 1994). Excitotoxic lesions of ventromedial PFC also suppress the development of (autonomically mediated) gastric stress ulcers, with right-sided PFC lesions alone fully accounting for this effect (Sullivan and Gratton, 1999). The same measure of stress pathology is aggravated by right-sided PFC DA depletion, suggesting that mesocortical DA in this area normally plays an adaptive role in preventing the overactivation of these cortical outputs which drive stress-induced sympathetic function (Sullivan and Szechtman, 1995).

The medial PFC is also important in hypothalamic-pituitary-adrenal (HPA) axis activation, as electrical stimulation in this area increases plasma corticosterone levels (Feldman and Conforti, 1985). Excitotoxic lesions which include the ventromedial PFC reduce stressinduced plasma corticosterone elevations, and again right-sided lesions alone account for this effect (Sullivan and Gratton, 1999). Lesions of more dorsal medial PFC sites on the other hand (prelimbic or anterior cingulate), have been reported to increase stress-induced plasma corticosterone levels (Diorio et al., 1993; Brake et al., 2000a). However, when lesions include both dorsal and ventromedial PFC (eg. Sullivan and Gratton, 1999), the ventral effects seem to 
predominate, perhaps owing to their more direct anatomical links with the relevant subcortical control centers.

In terms of stress-associated behaviors, mixed results have been reported in medial PFC lesion studies. In general, dorsomedial PFC damage tends to result in anxiogenic profiles (Holson et al., 1986; Morgan and LeDoux, 1995), while ventromedial damage results in anxiolytic effects (Frysztak and Neafsey, 1991; Gonzalez et al., 2000; Lacroix et al., 2000; Sullivan and Gratton, 2002b). As well, such anxiolytic effects have been reported following unilateral right, but not left, ventromedial damage (Sullivan and Gratton, 2002b). In contrast, ventromedial DA depletion enhances measures of anxiety, most likely due to a net reduction in inhibitory tone on these cortical outputs (Espejo, 1997).

The medial PFC DA system is not only extremely responsive to stress (eg. Thierry et al., 1976), but also exhibits many functional hemispheric asymmetries. Specifically, rightbiased mesocortical DA asymmetries have been associated with exposure to novel environments (Berridge et al., 1999), reduced anxiety in the elevated plus maze (Anderson and Teicher, 1999), protection from stress ulcer pathology (Sullivan and Szechtman, 1995), successful escape performance following exposure to uncontrollable shock (Carlson et al., 1993), performance accuracy in the 5CSRTT (Puumala and Sirvio, 1998) and stress-induced HPA activation (Sullivan and Gratton, 1998). It is suggested that these stress-sensitive DA afferents represent a high level coping system to optimize the broad range of functions subserved by the PFC, particularly in times of high arousal.

To summarize, the visceromotor cortex of the ventromedial PFC facilitates or drives sympathetic autonomic and neuroendocrine activity, particularly in times of stress, and contributes to anxiety-related (or perhaps cautious) behavior. These modes of physiological 
and behavioral arousal are a perfectly normal, if not essential, part of effective responding and coping with challenging situations, provided the degree of activation is appropriate and contained within reasonable limits. It is suggested that mesocortical DA contributes to the optimal functioning of these 'arousal output systems', by attempting to prevent their excessive activation, in essence by increasing the 'signal to noise ratio' in times of high stimulation.

In humans, it is now known that the ventromedial PFC is essential in regulating autonomic adjustments to emotional stimuli, and that the deficits in emotional self-regulation resulting from damage to this area, are linked as well to impaired risk assessment, planning and decision-making (Damasio, 1994; Damasio et al., 1990). Interestingly, these deficits appear to be mediated by right-sided damage alone (Tranel et al., 2002). It has also been proposed that right-sided orbital/medial prefrontal systems, under DAergic modulation, are responsible for generating stress-regulating coping strategies and optimal emotional self-regulation (Schore, 1996; 1997). The development of these systems is very much experience-dependent, not only on early social (maternal) attachment, but on a number of pre- and perinatal factors as well.

\section{Early Adverse Events and ADHD}

As acknowledged earlier, there is a strong genetic component in the occurrence of ADHD, which may well involve the aberrant development of DAergic frontostriatal circuitry. In addition however, a number of independent risk factors have been identified for subsequent ADHD diagnosis, which may affect the development of these same systems. In general, complications associated with pregnancy, delivery or infancy have been linked with increased risk of ADHD diagnosis (eg. Sprich-Buckminster et al., 1993; Milberger et al., 1997; King, 1996; Zappitelli et al., 2001; Rosa Neta et al., 2002). Specifically, factors involving reduced 
oxygen supply to the fetus or infant appear to be particularly important in this regard, both in familial and nonfamilial forms of the disorder. Such hypoxic conditions could be related to maternal bleeding, prenatal alcohol or drug abuse, which can affect placental circulation, or acute delivery complications (Sprich-Buckminster et al., 1993; Milberger et al., 1997; Ornoy et al., 2001; Bandstra et al., 2001; Mick et al., 2002). Toft (1999) has suggested that in neonates suffering from asphyxia, tissue hypoxia leads to excess lactate production, which may compromise development of frontostriatal circuitry, partially accounting for ADHD pathogenesis.

Hypoxic-ischemic events are especially common in prematurity, which may explain the high incidence of ADHD among children born prematurely with very low birth weight (Lou, 1996; Bhutta et al., 2002). A recent brain imaging study in ADHD adolescents with a history of prematurity and low birth weight, showed highly significant correlations between cerebral blood flow at the time of birth, symptom severity as adolescents and DA receptor binding, especially in the right frontostriatal system (Rosa et al., 2002).

In addition, a number of recent studies have highlighted the importance of the postnatal environment in predisposing to ADHD. Biederman et al. (1995) reported a positive association between a number of social adversity indicators and the risk for ADHD. It has been reported that deficits in the caregiving environment, including early problems in parental attachment contribute to ADHD development (Shaw et al., 2001; Halasz and Vance, 2002). In particular, less synchronous mother-child interactions were significantly associated with hyperactivity, a major predictor of which was maternal coping (Keown and Woodward, 2002). Very high levels of ADHD have also been reported among adopted youths, with the most notable preadoptive risk factors including early abuse/neglect (Simmel et al., 2001). It has also been 
found that early institutional rearing, in comparison to stable foster family rearing, predisposes to a pattern of hyperactivity/inattention (Roy et al., 2000). Moreover, in adoptees following severe early deprivation, the duration of deprivation was significantly associated with measures of inattention/overactivity, independent of numerous other risk factors (Kreppner et al., 2001). Finally, a PET imaging study has shown cerebral metabolism to be greatly affected by severe early deprivation, as a group of Romanian orphans were found to have significantly reduced activity in the orbital frontal gyrus and the infralimbic prefrontal

cortex, as well as some temporal lobe structures (Chugani et al., 2001). Such findings highlight the importance of not only prenatal conditions, but the postnatal social environment in the optimal maturation of these critical prefrontal and associated circuits.

\section{Effects of Early Developmental Manipulations on Rodent PFC Function}

The developing prefrontal cortex is extremely sensitive to a wide variety of perturbations. For example, prenatal stress leads to enhanced anxiety in the offspring, and lateralized changes in PFC DA function (Fride and Weinstock, 1988). Such treatments also produce lasting changes in both DA and glutamate receptor expression in medial PFC (eg. Berger et al., 2002). Similarly, cocaine exposure in utero results in offspring with dramatically increased levels of Fos protein expression selectively in the ventral and medial prefrontal regions (Morrow et al., 2002), as well as hyperresponsive DA activation in the ventromedial PFC in response to mild stress (Elsworth et al., 2001). The current review will focus on two other early developmental manipulations (viz. perinatal anoxia and early social environment) that also affect PFC development and produce changes in rat behavior and neurophysiology similar to some of those thought to occur in ADHD. 


\subsection{Effects of Perinatal Anoxia on DA Systems}

Some of the most relevant rodent studies in the context of ADHD concern the induction of perinatal hypoxic/anoxic states. Various protocols of anoxia induction have resulted in behavioral hyperactivity, which tends to peak during the juvenile period and abate toward the time of puberty, although some hyperactivity can persist (eg. Speiser et al., 1983; 1988, Brake et al., 2000b; Decker et al., 2003). Such treatments also produce lasting impairments in a number of learning and working memory tasks (Dell'Anna et al., 1991; Longo and Hermans, 1992; Decker et al., 2003). Increasing duration of anoxia at the time of delivery, leads to increasing degrees of postnatal cell death, most prominently in frontal cortex, striatum and cerebellum (Dell'Anna et al., 1997).

The brain of the newborn mammal is considered more resistant to anoxic episodes than the adult central nervous system (Haddad \& Donnelly, 1990; Jilek, 1970; Kabat, 1970). This is, in part, because of the low level of differentiation, and reduced metabolic demands, of immature neurons (Bickler et al., 1993; Nehlig and Pereira de Vasconselos, 1993) and the rich supply of anaerobic energy available to the newborn (Nehlig and Pereira de Vasconselos, 1993). Furthermore, acidosis occurs less easily due to the lack of a blood-brain barrier (Dombrowski et al., 1989; Nehlig \& Pereira de Vasconselos, 1993). It has been known for some time that this tolerance depends upon the immaturity of brain physiology during the perinatal period (Fazekas et al., 1941). Such conditions may protect immature neurons from the adverse effects of acute anoxia. Such an assumption has lead to the crudely held view that neonates are quite resistant to transient periods of anoxia. However, the resistance of the 
immature brain against anoxic episodes is a relative phenomenon and subtle damage can have pronounced consequences.

More subtle aspects of neuron development may be greatly influenced by perinatal anoxia. Although developing neurons may not require as much oxygen to survive they do require energy for structural differentiation processes such as axon and dendrite growth or synapse formation (Nyakas et al., 1996). A period of anoxia may interfere with the highly increased rate of synthesis of structural proteins and other macromolecules needed for proper development. Thus, perinatal anoxia may interfere with neuron differentiation and/or organization and as a consequence lead to subtle, albeit critical, changes in brain maturation.

Increasing evidence suggests that DA systems may be particularly vulnerable to the effects of perinatal anoxia. The following discussion reviews the long-term effects of perinatal anoxia on DA systems and DA-related behaviors. For a review of the long-term effects of neonatal hypoxia on other neurotransmitter systems see Nyakas et al. (1996).

It was Bjelke and colleagues (1991) who first developed a method of intra-uterine anoxia following $\mathrm{C}$-section delivery in the rat in order to study long-term effects of perinatal anoxia. This model minimizes the influence of surgical procedures and anesthesia inherent to most other models (e.g. Coyle, 1982; Pulsinelli \& Brierley, 1979). It also circumvents the problem of other hypoxia models of having to perform procedures pre- or post-natally when the pregnant dam or newborns, respectively, may be placed in a hypobaric chamber (Nyakas et al., 1996). It also has the advantage of studying the effects of $\mathrm{C}$-section delivery with differing amounts of additional anoxia, which may better represent birth complications cited in the clinical literature. 
It should be noted that periods of anoxia lasting 19 min. or longer cause brain pH levels to drop below 7 (Chen et al., 1997), at which point acidosis is sufficiently high to produce significant neuronal loss. Furthermore, periods of perinatal anoxia lasting $15 \mathrm{~min}$ or less result in a neonate survival rate close to $100 \%$ whereas $19-20$ min of anoxia results in $50-80 \%$ survival and periods of anoxia lasting longer than 22 min result in almost no pup survival (Chen et al., 1995; 1997; unpublished observations). Consequently, periods of anoxia lasting 19 min. or longer are more likely to produce more severe effects including massive cell loss and neuronal degeneration than shorter anoxic events (viz. 5 or $15 \mathrm{~min}$.). Perhaps, perinatal anoxia periods lasting $15 \mathrm{~min}$. or less are producing a different set of developmental sequelae than longer anoxic periods. It has been shown, for example, that perinatal anoxia periods of up to 15 min. produce significant increases of subcutaneous glutamate, pyruvate, and aspartate levels whereas longer anoxia periods do not (Dell'Anna et al., 1995). As such, this discussion will address those changes following more subtle periods (up to15 min) of perinatal anoxia. Studies employing longer periods of anoxia, which produce different developmental outcomes, will not be reviewed here.

Bjelke et al. (1991) observed enhanced TH-immunoreactivity in VTA and increased apomorphine-induced locomotor activity in rats that received $15 \mathrm{~min}$ of anoxia when compared to $\mathrm{C}$-section delivered animals. It has also been shown that $15 \mathrm{~min}$. of perinatal anoxia produces an increased locomotor response to acute amphetamine injection in the juvenile, fourweek-old, rat (Chen et al., 1995) and increases sensitization to acute amphetamine administration in the adult (Brake et al., 1997a). These rats also exhibit increased NAcc DA transmission in response to stress (Brake et al., 1997b). Increased NAcc DA D 1 receptor agonist affinity as well as increased $\mathrm{D}_{3}$ receptor binding in the striatum were observed in these 
animals (Chen et al., 1997); Chen et al., 1997 suggested that an increase in $\mathrm{D}_{3}$ receptor binding may be a result of a compensation for enhanced $\mathrm{D}_{1}$ receptor affinity.

Thus the most commonly reported changes following perinatal anoxia suggest a net upregulation of subcortical DA function (eg. Chen et al., 1997; Seidler and Slotkin, 1990; Brake et al., 1997). Employing other protocols, it has also been shown that anoxic rats show a $30 \%$ increase in stimulated dopamine release rate from striatal slices (Gross et al., 1993), and increases in striatal vesicular monoamine transporter and D1 receptor proteins (Decker et al., 2003).

Changes in prefrontal function have not been as frequently reported, perhaps owing in part to the limitations of some post mortem neurochemical studies and the less dense PFC DA innervation. For instance i) such measures may reflect the basal state of these systems rather than detecting changes seen when these systems are challenged ii) tissue samples may be too large to detect a discrete area of change and iii) samples of left and right cortex are normally pooled, eliminating the chance to detect hemisphere-specific effects. These limitations were overcome in a study by Brake et al. (2000b), employing in vivo voltammetric recordings of changes in extracellular DA levels in response to repeated mild stress, in rats which had received a 15 min intrauterine anoxia treatment in conjunction with Caesarean section birth. In comparison to vaginally born controls, anoxic rats not only displayed locomotor hyperactivity, but strikingly lateralized changes in mesocortical DA activation in ventromedial (infralimbic) PFC. While the left PFC DA response was unaffected by perinatal anoxia, the right PFC response was dramatically suppressed across all five days of testing. Moreover, it was shown in separate animals that DAT levels were elevated selectively in the right PFC, perhaps contributing to the reduced levels of extracellular DA. In keeping with the reciprocal nature of 
cortical/subcortical DA systems described earlier, Brake et al. (1997b) used the same technique to demonstrate that ventral striatal DA release is progressively enhanced or sensitized by repeated mild stress in anoxic animals. Taken together it was suggested that the 15 min anoxic episode induced a right mesocortical DA deficit, leading to a disinhibition of subcortical DA activity and subsequent behavioral hyperactivity; a scenario not unlike that proposed to explain ADHD pathophysiology (Castellanos, 1997).

\subsection{Effects of Postnatal Maternal Environment}

In addition to the developmental perturbations resulting from perinatal anoxia, the PFC is also sensitive to events occurring during the postnatal period. An extensive literature demonstrating the PFC sensitivity to postnatal manipulations within discrete developmental windows, especially in the context of recovery from PFC lesion, has been reviewed elsewhere (see Kolb et al., 2000 for a recent review). The postnatal social environment, particularly changes in maternal care, can also have significant effects on PFC development in the rat as well as in other species. Studies that have manipulated the postnatal social environment have reported significant changes in the development of prefrontal as well as DAergic systems. Two such examples, which can induce opposite changes in development, are neonatal handling $(\mathrm{H})$ and maternal separation (MS).

$\mathrm{H}$ involves a brief period (15 min) of daily separation of the rat dam from her pups, normally for the first two weeks of life, and is known to stimulate maternal behaviors (Liu et al., 1997) and impart numerous lasting benefits (Levine, 1975; Smotherman, 1983, Liu et al., 1997), in particular increased feedback regulation of stress and emotion regulatory systems. This enhanced feedback may be a consequence of the increased expression of glucocorticoid 
receptors (GR) in frontal cortex and hippocampus (Meaney et al., 1985; 1996; Diorio et al., 1993). $\mathrm{H}$ also affects cognition and prevents cognitive decline late in life (Meaney et al., 1991). Additionally, $\mathrm{H}$ reduces synaptic density in the stress-responsive infralimbic cortex (Ovtscharoff and Braun, 2001). Importantly for this discussion, H stimulates the normal right hemispheric lateralization of emotional regulation (Denenberg, 1981). Concomitantly, H appears to enhance the inhibitory capacity within the right PFC and hippocampus, in part by causing a rightward shift in benzodiazepine/GABA-A receptor binding in these structures, possibly preventing excessive emotional reactivity (Sullivan and Gratton, 2003). Moreover, the inhibitory modulatory role of mesocortical DA on stress-induced HPA activity is lateralized to the right $\mathrm{PFC}$ following $\mathrm{H}$, but is nonlateralized in $\mathrm{NH}$ rats (manuscript in preparation).

In contrast, MS involves longer daily separations in the first two to three weeks of life (normally in the range of $3-4.5$ hrs in rats) and results in hyperresponsive stress and emotion regulatory systems and enhanced fearfulness (Plotsky and Meaney, 1993; Meaney et al., 1996; Caldji et al., 2000; Ogawa et al., 1994). In addition to the behavioral effects, male offspring that received early MS show greater HPA activity as adults, both basally and in response to acute stress (Ladd et al., 2000; Liu et al., 2000; Plotsky and Meaney, 1993). Other studies in male rats show that MS decreases frontal cortex and hippocampal GR mRNA, reducing the capacity for HPA feedback regulation (Avishai-Eliner et al., 1999). Early postnatal MS and social isolation result in abnormally high synaptic density within the infralimbic cortex (Ovtscharoff and Braun, 2001), and altered densities of DAergic and serotonergic fibers throughout the medial PFC (Braun et al., 2000). Early social isolation also leads to decreased basal DA turnover, selectively in infralimbic cortex (Heidbreder et al., 2000). 
As was the case with perinatal anoxia, subcortical DA function appears to be upregulated by MS. Recent studies have shown that adult male MS rats are hyperactive and exhibit an exaggerated ventral striatal DA response to stress relative to $\mathrm{H}$ rats (Brake et al., submitted). MS rats also exhibit lower levels of DAT binding in dorsal and ventral striatum and are behaviorally hypersensitive to the locomotor-activating effects of cocaine (Meaney et al., 2002). These data clearly suggest that MS is capable of affecting the development of central DA systems thought to be involved in ADHD.

Interestingly, sex differences have been reported in the effects of MS, as this treatment does not appear to adversely affect females as much as males. For instance, female rats that were maternally separated as neonates, have been reported not to show the increase in fearrelated behaviors typical in males (Boccia and Pedersen, 2001; Wigger and Neumann, 1999). Furthermore, unlike males, female rats that have experienced MS do not show a heightened endocrine response to stress (Wigger and Neumann, 1999). Thus it appears that there is a sexspecific effect of the deleterious consequences from MS, which is preferentially male. Indeed, in mice, MS decreases indices of anxiety in adult female offspring while increasing it in males (Romeo et al., 2003) Although the mechanisms for such sex differences in MS rodents haven't been elucidated, they may have important ramifications for the higher incidence of neurodevelopmental disorders like ADHD observed in males compared to females.

Finally, a recent magnetic resonance imaging study in the non-human primate has demonstrated that MS results in a significant enlargement of the ventromedial PFC, specific to the right hemisphere (Lyons et al., 2002). Together with the above increases in synaptic density of this region, such findings may help explain the greatly heightened stress sensitivity and excessive arousal level of such animals. To conclude, it is clear that many factors affect the 
development of prefrontal systems, both in terms of the intrinsic structures within the PFC and their important afferent inputs, particularly the mesocortical DA system.

\section{Summary: Towards a better understanding prefrontal dysfunction in ADHD}

ADHD undoubtedly involves the abnormal development and functioning of entire networks of structures, not only prefrontal, but certainly striatal and even cerebellar (see Castellanos et al., 1996b; Castellanos and Tannock, 2002). What is presently proposed, is that right prefrontal cortex may play the most critical role in the expression of ADHD, by virtue of its direct role in mediating the core deficits of this condition, and by its regulation of striatal and other subcortical functions. The right PFC also appears to be particularly sensitive to early adverse events.

One of the most fundamental roles of the PFC appears to be the regulation of physiological and behavioral arousal levels, and the functional nature of these prefrontal arousal systems is greatly influenced by early environmental events. From optimal and situation-appropriate arousal regulation, follows the optimization of many interdependent functions mediated by the PFC, including responding to stress, emotional self-regulation, attentional control, working memory, temporal processing, planning, decision-making, and behavioral inhibition. Any developmental perturbations to the right PFC, due to genetic predisposition, early adverse events, or combinations thereof, would be expected to result in the suboptimal maturation and functioning of this region.

Either excessive, diminished or abnormally lateralized prefrontal activity can lead to a variety of forms of psychopathology (Sullivan and Gratton, 2002a). In the case of ADHD, the predominantly right lateralized nature of the pathology may derive from the inherent 
specialization of right hemispheric systems for arousal and stress regulation. Right brain mechanisms, particularly at the brainstem level, are more intimately linked with basic lifesustaining functions (e.g. autonomic regulation) and mature more rapidly than their left brain counterparts (Porges et al., 1995; Geschwind and Galaburda, 1987). However, the cortical representation or extension of these asymmetrical arousal networks is much slower to mature and vulnerable to insult for a much longer period. As such, early adverse events such as the metabolic stress of intrauterine hypoxia would be expected to impact preferentially on the development of these right-sided, physiology-regulating systems. Adverse or stressful events in later development or the early postnatal period would also be likely to alter the continued maturation of the right-sided prefrontal systems.

In the rat, cortical DA afferents start reaching their cortical targets earlier (final trimester of gestation) and achieve their adult innervation pattern later (roughly 2 months or puberty) than other major cortical afferent systems (fig. 1), giving this key regulatory system a particularly long window of vulnerability to insult (Berger-Sweeney and Hohmann, 1997). This system is also said to be slower maturing in males than females, perhaps partially accounting for the higher incidence of ADHD in boys. Even if developmental anomalies in mesocortical DA systems were entirely related to genetic predisposition, the long-term pathology would still be expected to be asymmetrical, since central DA systems in the normal rat are known to be functionally asymmetrical at least from the time of birth if not sooner (Afonso et al., 1993; Rodriguez et al., 1994; Varlinskaya et al., 1995).

While many questions remain unanswered regarding ADHD, it is clear that rodent studies, particularly on the nature of PFC function, have and will continue to shed considerable light on many of the clinical observations reported in ADHD. It is hoped that future animal 
studies which attempt to model at least aspects of ADHD, whether they involve the knock-out of candidate genes, effects of intrauterine hypoxia, neuropharmacological or other approaches, will include the careful examination of the effects of their manipulations on prefrontal function, particularly that of the right hemisphere. There is still a great deal to be learned concerning the development of these critical prefrontal systems, not the least of which is the potential means of reversing, or best compensating for, their suboptimal development. 


\section{References}

[1] Afonso D, Santana C, Rodriguez M. Neonatal lateralization of behavior and brain dopaminergic asymmetry. Brain Res Bull, 1993; 32: 11-16.

[2] Alexander GE, DeLong MR, Strick PL. Parallel organization of functionally segregated circuits linking basal ganglia and cortex. Ann Rev Neurosci, 1986; 9 : 357-381.

[3] Althaus M, Mulder LJ, Mulder G, Aarnoudse CC, Minderaa RB. Cardiac adaptivity to attention-demanding tasks in children with a pervasive developmental disorder not otherwise specified (PDD-NOS). Biol Psychiat, 1999; 46(6): 799-809.

[4] Anderson SL, Teicher MH. Serotonin laterality in amygdala predicts performance in the elevated plus maze. Neuroreport, 1999; 10: 3497-3500.

[5] Avishai-Eliner S, Hatalski CG. Tabachnik E, Eghbal-Ahmadi M, Baram TZ. Differential regulation of glucocorticoid receptor messenger RNA (GR-mRNA) by maternal deprivation in immature rat hypothalamus and limbic regions. Brain Res Dev Brain Res, 1999; 114(2): 265-268. 
[6] Bacon SJ, Smith AD. A monosynaptic pathway from an identified vasomotor centre in the medial prefrontal cortex to an autonomic area in the thoracic spinal cord. Neuroscience, 1993; 54: 719-728.

[7] Bandstra ES, Morrow CE, Anthony JC, Accornero VH, Fried PA. Longitudinal investigation of task persistence and sustained attention in children with prenatal cocaine exposure. Neurotoxicol Teratol, 2001; 23(6): 545-59.

[8] Banks KE, Gratton A. Possible involvement of prefrontal cortex in amphetamine-induced sensitization of mesolimbic dopamine function in rat. Eur J Pharmacol, 1995; 282: 157167.

[9] Barkley, RA. Behavioral inhibition, sustained attention, and executive functions: constructing a unifying theory of ADHD. Psychol Bull, 1997; 121(1): 65-94.

[10] Barkley RA. Attention-deficit hyperactivity disorder. Sci Amer, 1998; 9(Sept): 66-71.

[11] Beauchaine TP, Katkin ES, Strassberg Z, Snarr J. Disinhibitory psychopathology in male adolescents: discriminating conduct disorder from attention-deficit/hyperactivity disorder through concurrent assessment of multiple autonomic states. J Abnorm Psychol, 2001; 110(4): 610-624. 
[12] Berger MA, Barros VG, Sarchi MI, Tarazi FI, Antonelli MC. Long-term effects of prenatal stress on dopamine and glutamate receptors in adult rat brain. Neurochem Res, 2002; 27(11): 1525-33.

[13] Berger-Sweeney J, Hohmann CF. Behavioral consequences of abnormal cortical development: insights into developmental disabilities. Behav Brain Res, 1997; 86: 121-142.

[14] Berridge CW, Mitton E, Clark W, Roth RH. Engagement in a non-escape (displacement) behavior elicits a selective and lateralized suppression of frontal cortical dopaminergic utilization in stress. Synapse, 1999; 32: 187-197.

[15] Beyer CE, Steketee JD. Dopamine depletion in the medial prefrontal cortex induces sensitized-like behavioral and neurochemical responses to cocaine. Brain Res, 1999; 833(2): 133-141.

[16] Beyer CE, Steketee JD. Intra-medial prefrontal cortex injection of quinpirole, but not SKF 38393, blocks the acute motor-stimulant response to cocaine in the rat. Psychopharmacology (Berl), 2000; 151(2-3): 211-218.

[17] Bhutta AT, Cleves MA, Casey PH, Cradock MM, Anand KJ. Cognitive and behavioral outcomes of school-aged children who were born preterm: a meta-analysis. JAMA, 2002; 288(6): 728-37. 
[18] Bickler PE, Gallego SM, Hansen BM. Developmental changes in intracellular calcium regulation in rat cerebral cortex during hypoxia. J Cerebral Blood Flow Metab, 1993; 13: 811-819.

[19] Biederman J, Milberger S, Faraone SV, Kiely K, Guite J, Mick E, Ablon S, Warburton R, Reed E. Family-environment risk factors for attention-deficit hyperactivity disorder. A test of Rutter's indicators of adversity. Arch Gen Psychiat, 1995; 52(6): 464-70.

[20] Bjelke B, Andersson K, Ögren SO, Bolme P. Asphyctic Lesion: proliferation of tyrosine hydroxylase-immunoreactive nerve cell bodies in the rat substantia nigra and functional changes in dopamine transmission. Brain Res, 1991; 543: 1-9.

[21] Boccia ML, Pedersen CA. Brief vs. long maternal separations in infancy: contrasting relationships with adult maternal behavior and lactation levels of aggression and anxiety. Psychoneuroendocrinology, 2001; 26: 657-672.

[22] (a) Brake WG, Boksa P, Gratton A. Effects of perinatal anoxia on the acute locomotor response to repeated amphetamine administration in adult rats. Psychopharmacology, 1997; 133: 389-395.

[23] (a) Brake WG, Flores G, Francis D, Meaney MJ, Srivastava LK, Gratton A. Enhanced nucleus accumbens dopamine and plasma corticosterone stress responses in adult rats with 
neonatal excitotoxic lesions to the medial prefrontal cortex. Neuroscience, 2000; 96(4): 687-695.

[24] Brake WG, Meaney MJ, Gratton A. Influence of early postnatal rearing conditions on mesocorticolimbic dopamine and behavioral responses to psychostimulants and stress in adult rats. Submitted.

[25] (b) Brake WG, Noel MB, Boksa P, Gratton A. Influence of perinatal factors on the nucleus accumbens dopamine response to repeated stress during adulthood: an electrochemical study in the rat. Neuroscience, 1997; 77: 1067-1076.

[26] (b) Brake WG, Sullivan RM, Gratton A. Perinatal distress leads to lateralized medial prefrontal cortical dopamine hypofunction in adult rats. J Neurosci, 2000; 20(14): 55385543.

[27] Braun K, Lange E, Metzger M, Poeggel G. Maternal separation followed by early social deprivation affects the development of monoaminergic fiber systems in the medial prefrontal cortex of Octodon degus. Neuroscience, 2000; 95: 309-318.

[28] Bymaster FP, Katner JS, Nelson DL, Hemrick-Luecke SK, Threlkeld PG, Heiligenstein JH, Morin SM, Gehlert DR, Perry KW. Atomoxetine increases extracellular levels of norepinephrine and dopamine in prefrontal cortex of rat: a potential mechanism for efficacy 
in attention deficit/hyperactivity disorder. Neuropsychopharmacology, 2002; 27(5): 699711.

[29] Campbell L, Malone MA, Kershner JR, Roberts W, Humphries T, Logan, WJ. Methylphenidate slows right hemisphere processing in children with attentiondeficit/hyperactivity disorder. J Child Adolesc Psychopharmacol, 1996; 6(4): 229-39.

[30] Carlson JN, Fitzgerald LW, Keller RW, Glick SD. Lateralized changes in prefrontal cortical dopamine activity induced by controllable and uncontrollable stress in the rat. Brain Res, 1993; 630: 178-187.

[31] Carter CS, Krener P, Chaderjian M, Northcutt C, Wolfe V. Asymmetrical visual-spatial attentional performance in ADHD: evidence for a right hemispheric deficit. Biol Psychiat, 1995; 37(11): 789-97.

[32] Casey BJ, Castellanos FX, Giedd JN, Marsh WL, Hamburger SD, Schubert AB, Vauss YC, Vaituzis AC, Dickstein DP, Sarfatti SE, Rapoport JL. Implication of right frontostriatal circuitry in response inhibition and attention-deficit/hyperactivity disorder. J Am Acad Child Adolesc Psychiat, 1997; 36(3): 374-83.

[33] Castellanos FX. Toward a pathophysiology of attention-deficit/ hyperactivity disorder. Clin Pediat, 1997; 37: 381-393. 
[34] (a) Castellanos FX, Elia J, Kruesi MJ, Marsh WL, Gulotta CS, Potter WZ, Ritchie GF, Hamburger SD, Rapoport JL. Cerebrospinal fluid homovanillic acid predicts behavioral response to stimulants in 45 boys with attention deficit/hyperactivity disorder. Neuropsychopharmacology, 1996; 14(2): 125-37.

[35] (b) Castellanos FX, Giedd JN, Marsh WL, Hamburger SD, Vaituzis AC, Dickstein DP, Sarfatti SE, Vauss YC, Snell JW, Lange N, Kaysen D, Krain AL, Ritchie G, Rajapakse JC, Rapoport JL. Quantitative brain magnetic resonance imaging in attention-deficit hyperactivity disorder. Arch Gen Psychiat, 1996; 53(7): 607-16.

[36] Castellanos FX Tannock R. Neuroscience of attention-deficit/hyperactivity disorder: the search for endophenotypes. Nature Reviews, 2002; 3: 617-628.

[37] Cechetto DF Saper CB. Role of the cerebral cortex in autonomic function. In: Loewy AD, Spyer KM, editors. Central Regulation of Autonomic Functions. Oxford: Oxford University Press, 1990, 208-223.

[38] Chen Y, Engidawork E, Loidl F, Dell'Anna E, Goiny M, Lubec G, Andersson K, Herrera-Marschitz M. Short- and long-term effects of perinatal asphyxia on monoamine, amino acid and glycolysis product levels measured in the basal ganglia of the rat. Brain Res Dev Brain Res, 1997; 104(1-2): 19-30. 
[39] Chen Y, Ögren S-O, Bjelke B, Bolme P, Eneroth P, Gross J, Loidl F, Herrera-Marschitz M, Andersson K. Nicotine treatment counteracts perinatal asphyxia-induced changes in the mesostriatal/limbic dopamine systems and in motor behaviour in the four-week-old male rat. Neuroscience, 1995; 68: 531-538.

[40] Chugani HT, Behen ME, Muzik O, Juhasz C, Nagy F, Chugani DC. Local brain functional activity following early deprivation: a study of postinstitutionalized Romanian orphans. Neuroimage, 2001; 14(6): 1290-301.

[41] Cook EH Jr, Stein MA, Krasowski MD, Cox NJ, Olkon DM, Kieffer JE, Leventhal BL. Association of attention-deficit disorder and the dopamine transporter gene. Am J Human Genet, 1995; 56: 993-998.

[42] Coyle C. Middle cerebral artery occlusion in the young rat. Stroke, 1982; 6: 855-859.

[43] Damasio AR. Descartes' Error. New York: Grosset/Putnam, 1994.

[44] Damasio AR, Tranel D, Damasio H. Individuals with sociopathic behavior caused by frontal damage fail to respond autonomically to social stimuli. Behav Brain Res, 1990; 41: 81-94. 
[45] Decker MJ, Hue GE, Caudle WM, Miller GW, Keating GL, Rye DB. Episodic neonatal hypoxia evokes executive dysfunction and regionally specific alterations in markers of dopamine signaling. Neuroscience, 2003; 117(2): 417-25.

[46] Dell'Anna E, Chen Y, Engidawork E, Andersson K, Lubec G, Luthman J, HerreraMarschitz M. Delayed neuronal death following perinatal asphyxia in the rat. Exp Brain Res, 1997; 115: 105-115.

[47] Dell'Anna ME, Calzolari S, Molinari M, Iuvone L, Calimici R. Neonatal anoxia induces transitory hyperactivity, permanent spatial memory deficits and CA1 cell density reduction in developing rats. Behav Brain Res, 1991; 45: 125-134.

[48] Denenberg VH. Hemispheric laterality in animals and the effects of early experience. Behav Brain Sci, 1981; 4: 1-49.

[49] Deutch, AY, Clark WA, Roth RH. Prefrontal cortical dopamine depletion enhances the responsiveness of mesolimbic dopamine neurons to stress. Brain Res, 1990; 521: 311-315.

[50] Diorio D, Viau V, Meaney MJ. The role of the medial prefrontal cortex (cingulate cortex) in the regulation of hypothalamic-pituitary-adrenal responses to stress. J Neurosci, 1993; 13: 3839-3847. 
[51] Doherty MD, Gratton A. Medial prefrontal cortical D1 receptor modulation of the meso-accumbens dopamine response to stress: an electrochemical study in freely-behaving rats. Brain Res, 1996; 715: 86-97.

[52] Dombrowski GJ, Swiatek KR, Chao K. Lactate, 3-hydroxybutyrate and glucose as substrates for the early postnatal rat brain. Neurochem Res, 1989; 14: 667-675.

[53] Elsworth JD, Morrow BA, Roth RH. Prenatal cocaine exposure increases mesoprefrontal dopamine neuron responsivity to mild stress. Synapse, 2001; 42: 80-83.

[54] Ernst M, Zametkin AJ, Matochik JA, Jons PH, Cohen RM. DOPA decarboxylase activity in attention deficit hyperactivity disorder adults. J Neurosci, 1998; 18: 5901-5907.

[55] Espejo EF. Selective dopamine depletion within the medial prefrontal cortex induces anxiogenic-like effects in rats placed on the elevated plus maze. Brain Res, 1999; 762 : 281-284.

[56] Fazekas JF, Alexander FAD, Himwich HE. Tolerance of the newborn to anoxia. Amer J Physiol, 1941; 134: 281-287.

[57] Feldman S, Conforti N. Modifications of adrenocortical responses following frontal cortex stimulation in rats with hypothalamic deafferentations and medial forebrain bundle lesions. Neuroscience, 1985; 15: 1045-1047. 
[58] Filipek PA, Semrud-Clikeman M, Steingard RJ, Renshaw PF, Kennedy DN, Biederman J. Volumetric MRI analysis comparing subjects having attention-deficit hyperactivity disorder with normal controls. Neurology, 1997; 48(3): 589-601.

[59] Floresco SB, Phillips AG. Delay-dependent modulation of memory retrieval by infusion of a dopamine D1 agonist into the rat medial prefrontal cortex. Behav Neurosci, 2001; 115(4): 934-9.

[60] Fride E, Weinstock M. Prenatal stress increases anxiety related behavior and alters cerebral lateralization of dopamine activity. Life Science, 1998; 42: 1059-1065.

[61] Frysztak RJ, Neafsey EJ. The effect of medial frontal cortex lesions on respiration, "freezing," and ultrasonic vocalizations during conditioned emotional responses in rats. Cerebr Cortex, 1991; 1: 418-425.

[62] Frysztak RJ, Neafsey EJ. The effect of medial frontal cortex lesions on cardiovascular conditioned emotional responses in the rat. Brain Res, 1994; 643: 181-193.

[63] Garavan H, Ross TJ, Stein EA. Right hemispheric dominance of inhibitory control: an event-related functional MRI study. Proc Natl Acad Sci USA, 1999; 96(14): 8301-8306. 
[64] Geshwind N, Galaburda AM. Cerebral Lateralization: Biological Mechanisms, Associations, and Pathology. Cambridge: MIT Press, 1987.

[65] Gill M, Daly G, Heron S, Hawi Z, Fitzgerald M. Confirmation of association between attention deficit disorder and a dopamine transporter polymorphism. Mol Psychiat, 1997; 2: 311-313.

[66] Gonzalez LE, Rujano M, Tucci S, Paredes D, Silva E, Alba G, Hernandez L. Medial prefrontal transection enhances social interaction. I: behavioral studies. Brain Res, 2000; 887: 7-15.

[67] Granon S, Passetti F, Thomas KL, Dalley JW, Everitt BJ, Robbins TW. Enhanced and impaired attentional performance after infusion of D1 dopaminergic receptor agents into rat prefrontal cortex. J Neurosci, 2000; 20(3): 1208-15.

[68] Gresch PJ, Sved AF, Zigmond MJ, Finlay JM. Local influence of endogenous norepinephrine on extracellular dopamine in rat medial prefrontal cortex. J Neurochem, 1995; 65(1): 111-116.

[69] Gross J, Lun A, Berndt C. Early postnatal hypoxia induces long-term changes in the dopaminergic system in rats. J Neural Transm Gen Sect, 1993; 93(2): 109-21. 
[70] Gross J, Muller I, Chen Y, Elizalde M, Leclere N, Herrera-Marschitz M, Andersson K. Perinatal asphyxia induces region-specific long-term changes in mRNA levels of tyrosine hydroxylase and dopamine $\mathrm{D}(1)$ and $\mathrm{D}(2)$ receptors in rat brain. Brain Res Mol Brain Res, 2000; 79(1-2): 110-7.

[71] Haddad GG, Donelly DF. $\mathrm{O}_{2}$ deprivation induces a major depolarization in brainstem neurons in the adult but not in the neonate. J Physiol (London), 1990; 429: 411-428.

[72] Halasz G, Vance AL. Attention deficit hyperactivity disorder in children: moving forward with divergent perspectives. Med J Aust, 2002; 177(10): 554-7.

[73] Hawi Z, Lowe N, Kirley A, Gruenhage F, Nothen M, Greenwood T, Kelsoe J, Fitzgerald M, Gill M. Linkage disequilibrium mapping at DAT1, DRD5 and DBH narrows the search for ADHD susceptibility alleles at these loci. Mol Psychiat, 2003; 8(3): 299-308.

[74] Heidbreder CA, Weiss IC, Domeney AM, Pryce C, Homberg J, Hedou G, Feldon J, Moran MC, Nelson P. Behavioral, neurochemical and endocrinological characterization of the early social isolation syndrome. Neuroscience, 2000; 100(4): 749-68.

[75] Heilman KM, Voeller KK, Nadeau SE. A possible pathophysiologic substrate of attention deficit hyperactivity disorder. J Child Neurol, 1991; 6 Suppl: S76-81. 
[76] Holson RR. Mesial prefrontal cortical lesions and timidity in rats. I. Reactivity to aversive stimuli. Physiol Behav, 1986; 37: 221-230.

[77] Hurley KM, Herbert H, Moga MM, Saper CB. Efferent projections of the infralimbic cortex of the rat. J Comp Neurol, 1991; 308 : 249-276.

[78] Jaskiw GE, Weinberger DR, Crawley JN. Microinjection of apomorphine into the prefrontal cortex of the rat reduces dopamine metabolite concentrations in microdialysate from the caudate nucleus. Biol Psychiat, 1991; 29: 703-706.

[79] Jilek L. The reaction and adaptation of the central nervous system to stagnant hypoxia and anoxia during ontogeny. In: Himwich WA, editor. Developmental Neurobiology. Springfield: Charles C. Thomas, 1990, 391-420.

[80] Jodo E, Chiang C, Aston-Jones G. Potent excitatory influence of prefrontal cortex activity on noradrenergic locus coeruleus neurons. Neuroscience 1998; 83(1): 63-79.

[81] Kabat H. The greater resistance of very young animals to arrest of the brain circulation. Amer J Physiol, 1970; 130: 588-599.

[82] Kaneko M, Hoshino Y, Hashimoto S, Okano T, Kumashiro H. Hypothalamic-pituitaryadrenal axis function in children with attention-deficit hyperactivity disorder. $\mathrm{J}$ Autism Dev Disord, 1993; 23(1): 59-65. 
[83] Kariyawasam SH, Zaw F, Handley SL. Reduced salivary cortisol in children with comorbid attention deficit hyperactivity disorder and oppositional defiant disorder. Neuroendocrinol Lett, 2002; 23(1): 45-48.

[84] Kempton S, Vance A, Maruff P, Luk E, Costin J, Pantelis C. Executive function and attention deficit hyperactivity disorder: stimulant medication and better executive function performance in children. Psychol Med, 1999; 29(3): 527-38.

[85] Keown LJ, Woodward LJ. Early parent-child relations and family functioning of preschool boys with pervasive hyperactivity. J Abnorm Child Psychol, 2002; 30 (6): 541553.

[86] King JA. Perinatal stress and impairment of the stress response: possible link to nonoptimal behavior. Ann NY Acad Sci, 1996; 794: 104-112.

[87] King JA, Barkley RA, Barrett S. Attention-deficit hyperactivity disorder and the stress response. Biol Psychiat, 1998; 44(1): 72-74.

[88] Kirley A, Hawi Z, Daly G, McCarron M, Mullins C, Millar N, Waldman I, Fitzgerald M, Gill M. Dopaminergic System Genes in ADHD. Toward a Biological Hypothesis. Neuropsychopharmacology, 2002; 27(4): 607. 
[89] Kolb B, Gibb R, Gorny G. Cortical plasticity and the development of behavior after early frontal cortical injury. Dev Neuropsychol. 2000; 18(3): 423-44.

[90] Kratochvil CJ, Heiligenstein JH, Dittmann R, Spencer TJ, Biederman J, Wernicke J, Newcorn JH, Casat C, Milton D, Michelson D. Atomoxetine and methylphenidate treatment in children with ADHD: a prospective, randomized, open-label trial. Am Acad Child Adolesc Psychiatry, 2002; 41(7): 776-84.

[91] Kreppner JM, O'Connor TG, Rutter M. Can inattention/overactivity be an institutional deprivation syndrome? J Abnorm Child Psychol, 2001; 29(6): 513-28.

[92] Kubos KL, Pearlson GD, Robinson RG. Intracortical kainic acid induces an asymmetrical behavioral response in the rat. Brain Res, 1982; 239: 303-309.

[93] Lacroix L, Spinelli S, Heidbreder CA, Feldon J. Differential role of the medial and lateral prefrontal cortices in fear and anxiety. Behav Neurosci, 2000; 114(6): 1119-30.

[94] Langleben DD, Austin G, Krikorian G, Ridlehuber HW, Goris ML, Strauss HW. Interhemispheric asymmetry of regional cerebral blood flow in prepubescent boys with attention deficit hyperactivity disorder. Nucl Med Commun, 2001; 22(12): 1333-1340. 
[95] Lazzaro I, Gordon E, Li W, Lim CL, Plahn M, Whitmont S, Clarke S, Barry RJ, Dosen A, Meares R. Simultaneous EEG and EDA measures in adolescent attention deficit hyperactivity disorder. Int J Psychophysiol, 1999; 34(2): 123-134.

[96] Levine S. Infantile experience and resistance to physiological stress. Science, 1975; 126: 405-406.

[97] Liu D, Diorio J, Tannenbaum B, Caldji C, Francis D, Freedman A, Sharma S, Pearson D, Plotsky PM, Meaney MJ. Maternal care, hippocampal glucocorticoid receptors, and hypothalamic-pituitary-adrenal responses to stress. Science, 1997; 277: 1659-1662.

[98] Longo LD, Hermans RH. Behavioral and neurochemical sequelae in young rats of antenatal hypoxia. Early Hum Dev, 1992; 29(1-3): 83-90.

[99] Lou HC. Etiology and pathogenesis of attention-deficit hyperactivity disorder (ADHD): significance of prematurity and perinatal hypoxic-haemodynamic encephalopathy. Acta Paediatr, 1996; 85(11): 1266-1271.

[100] Lyons DM, Afarian H, Schatzberg AF, Sawyer-Glover A, Moseley ME. Experiencedependent asymmetric variation in primate prefrontal morphology. Behav Brain Res, 2002; 136: 51-59. 
[101] Malone MA, Kershner JR, Siegel L. The effects of methylphenidate on levels of processing and laterality in children with attention deficit disorder. J Abnorm Child Psychol, 1998; 16(4): 379-395.

[102] McDonald S, Bennett KM, Chambers H, Castiello U. Covert orienting and focusing of attention in children with attention deficit hyperactivity disorder. Neuropsychologia, 1999; 37(3): 345-356.

[103] Meaney MJ, Aitken DH, Bodnoff SR, Iny LJ, Tatarewicz JE, Sapolsky RM. Early postnatal handling alters glucocorticoid receptor concentrations in selected brain regions. Behav Neurosci, 1985; 99(4): 765-770.

[104] Meaney MJ, Brake W, Gratton A. Environmental regulation of the development of mesolimbic dopamine systems: a neurobiological mechanism for vulnerability to drug abuse? Psychoneuroendocrinology, 2002; 27(1-2): 127-38.

[105] Meaney MJ, Diorio J, Francis D, Widdowson J, LaPlante P, Caldji C, Sharma S, Seckl JR, Plotsky PM. Early environmental regulation of forebrain glucocorticoid receptor gene expression: implications for adrenocortical responses to stress. Dev Neurosci, 1996; 18(12): 49-72.

[106] Meaney MJ, Mitchell JB, Aitken DH, Bhatnagar S, Bodnoff SR, Iny LJ, Sarrieau A. The effects of neonatal handling on the development of the adrenocortical response to 
stress: implications for neuropathology and cognitive deficits in later life. Psychoneuroendocrinology, 1991; 16(1-3): 85-103.

[107] Mehta MA, Owen AM, Sahakian BJ, Mavaddat N, Pickard JD, Robbins TW. Methylphenidate enhances working memory by modulating discrete frontal and parietal lobe regions in the human brain. J Neurosci, 2000; 20(6): RC65.

[108] Mick E, Biederman J, Faraone SV, Sayer J, Kleinman S. Case-control study of attention-deficit hyperactivity disorder and maternal smoking, alcohol use, and drug use during pregnancy. J Am Acad Child Adolesc Psychiat, 2002; 41(4): 378-85.

[109] Milberger S, Biederman J, Farone SV, Guite J, Tsuang MT. Pregnancy, delivery and infancy complications and attention-deficit hyperactivity disorder: issues of geneenvironment interaction. Biol Psychiat, 1997; 41: 65-75.

[110] Mitchell JB, Gratton A. Partial dopamine depletion of the prefrontal cortex leads to enhanced mesolimbic dopamine release elicited by repeated exposure to naturally reinforcing stimuli. J. Neurosci, 1992; 12: 3609-3618.

[111] Mizoguchi K, Yuzurihara M, Ishige A, Sasaki H, Chui DH, Tabira T. Chronic stress induces impairment of spatial working memory because of prefrontal dopaminergic dysfunction. J Neurosci, 2000; 20(4) : 1568-74. 
[112] Morgan ME, LeDoux JE. Differential contribution of dorsal and ventral medial prefrontal cortex to the acquisition and extinction of conditioned fear in rats. Behav Neurosci 1995; 109: 681-688.

[113] Morrow BA, Elsworth JD, Roth RH. Male rats exposed to cocaine in utero demonstrate elevated expression of Fos in the prefrontal cortex in response to environment. Neuropsychopharmacology, 2002; 26(3): 275-85.

[114] Mostofsky S, Cooper K, Kates W, Denckla M, Kaufmann W. Smaller prefrontal and premotor volumes in boys with attention-deficit/hyperactivity disorder. Biol Psychiat, 2002; 52(8): 785 .

[115] Muller U, von Cramon DY, Pollmann S. D1- versus D2-receptor modulation of visuospatial working memory in humans. J Neurosci, 1998; 18(7): 2720-2728.

[116] Murphy BL, Arnsten AF, Goldman-Rakic PS, Roth RH. Increased dopamine turnover in the prefrontal cortex impairs spatial working memory performance in rats and monkeys. Proc Natl Acad Sci USA, 1996; 93(3): 1325-1329.

[117] Nyakas C, Buwalda B, Luiten PGM. Hypoxia and brain development. Prog Neurobiol, 1996; 49: 1-51. 
[118] Nehlig A, Pereira de Vasconselos A. Glucose and ketone body utilization by the brain of neonatal rats. Prog Neurobiol, 1993; 40: 163-221.

[119] Ornoy A, Segal J, Bar-Hamburger R, Greenbaum C. Developmental outcome of school-age children born to mothers with heroin dependency: importance of environmental factors. Dev Med Child Neurol, 2001; 43(10): 668-75.

[120] Ovtscharoff W Jr, Braun K. Maternal separation and social isolation modulate the postnatal development of synaptic composition in the infralimbic cortex of Octodon degus. Neuroscience, 2001; 104: 33-40.

[121] Pearlson GD, Robinson RG. Suction lesions of the frontal cerebral cortex in the rat induce asymmetrical behavioral and catecholaminergic responses. Brain Res, 1981; 218: 233-242.

[122] Plotsky PM, Meaney MJ. Early, postnatal experience alters hypothalamic corticotropinreleasing factor (CRF) mRNA, median eminence CRF content and stress-induced release in adult rats. Brain Res Mol Brain Res, 1983; 18(3): 195-200.

[123] Porges SW. Cardiac vagal tone: A physiological index of stress. Neurosci Biobehav Rev, 1995; 19: 225-233. 
[124] Powell DA, Watson K, Maxwell B. Involvement of subdivisions of the medial prefrontal cortex in learned cardiac adjustments in rabbits. Behav Neurosci 1994; 108: 294307.

[125] Price JL. Prefrontal cortical networks related to visceral function and mood. Ann. N.Y. Acad Sci, 1999; 877: 383-396.

[126] Pueyo R, Maneru C, Vendrell P, Mataro M, Estevez-Gonzalez A, Garcia-Sanchez C, Junque C. Attention deficit hyperactivity disorder. Cerebral asymmetry observed on magnetic resonance. Rev Neurol, 2000; 30(10): 920-925.

[127] Pulsinelli W. Brierly JA. A new model of bilateral hemispheric ischemia in the unanesthesized rat. Stroke, 1979; 10: 267-272.

[128] Puumala T, Ruotsalainen S, Jakala P, Koivisto E, Riekkinen P Jr, Sirvio J. Behavioral and pharmacological studies on the validation of a new animal model for attention deficit hyperactivity disorder. Neurobiol Learn Mem, 1996; 66(2): 198-211.

[129] Puumala T, Sirvio J. Changes in activities of dopamine and serotonin systems in the frontal cortex underlie poor choice accuracy and impulsivity of rats in an attention task. Neuroscience, 1998; 83(2): 489-99. 
[130] Pycock CJ, Carter CJ, Kerwin RW. Effect of 6-hydroxydopamine lesions of the medial prefrontal cortex on neurotransmitter systems in subcortical sites in the rat. J. Neurochem,. 1980; 34: 91-99.

[131] Robbins TW. From arousal to cognition: the integrative position of the prefrontal cortex. Prog Brain Res, 2000; 126: 469-83.

[132] Robbins TW. The 5-choice serial reaction time task: behavioural pharmacology and functional neurochemistry. Psychopharmacology (Berl), 2002; 163(3-4): 362-80.

[133] Robinson RG. Differential behavioral and biochemical effects of right and left hemispheric cerebral infarction in the rat. Science, 1975; 205: 707-710.

[134] Robinson RG, Stitt TG. Intracortical 6-hydroxydopamine induced an asymmetrical behavioral response in the rat. Brain Res, 1981; $213: 387-395$.

[135] Rodriguez M, Martin L, Santana C. Ontogenic development of brain asymmetry in dopaminergic neurons. Brain Res Bull, 1994; 33: 163-171.

[136] Romeo RD, Mueller A, Sisti HM, Ogawa S, McEwen BS, Brake WG. Anxiety and fear behaviors in adult male and female C57BL/6 mice are modulated by maternal separation. Hormones Behav, 2003; in press. 
[137] Rosa P, Lou HC, Cumming P, Pryds O, Gjedde A. Dopamine $\mathrm{D}_{2-3}$ receptor availability in adolescents with ADHD linked to low cerebral blood flow at birth. Soc Neurosci Abs, 2002; Vol 28 [online].

[138] Rosa Neto P, Lou H, Cumming P, Pryds O, Gjedde A. Methylphenidate-evoked potentiation of extracellular dopamine in the brain of adolescents with premature birth: correlation with attentional deficit. Ann N Y Acad Sci, 2002; 965: 434-439.

[139] Rosin DL, Clark WA, Goldstein M, Roth RH, Deutch AY. Effects of 6hydroxydopamine lesions of the prefrontal cortex on tyrosine hydroxylase activity in mesolimbic and nigrostriatal dopamine systems. Neuroscience, 1992; 48: 831-839.

[140] Roy P, Rutter M, Pickles A. Institutional care: risk from family background or pattern of rearing? J Child Psychol Psychiat, 2000; 41(2): 139-49.

[141] Rubia K, Overmeyer S, Taylor E, Brammer M, Williams SC, Simmons A, Bullmore ET. Hypofrontality in attention deficit hyperactivity disorder during higher-order motor control: a study with functional MRI. Am J Psychiat,1999; 156(6): 891-896.

[142] Rubia K, Taylor E, Smith AB, Oksanen H, Overmeyer S, Newman S, Oksannen H. Neuropsychological analyses of impulsiveness in childhood hyperactivity. Br J Psychiat, $2001 ; 179: 138-143$. 
[143] Sawaguchi T. The effects of dopamine and its antagonists on directional delay-period activity of prefrontal neurons in monkeys during an oculomotor delayed-response task. Neurosci Res, 2001; 41(2): 115-128.

[144] Sawaguchi T, Goldman-Rakic PS. D1 dopamine receptors in prefrontal cortex: involvement in working memory. Science, 1991; 251: 947-950.

[145] Schore AN. The experience-dependent maturation of a regulatory system in the orbital prefrontal cortex and the origin of developmental psychopathology. Dev Psychopathol, 1996; 8: 59-87.

[146] Schore AN. Early organization of the nonlinear right brain and development of a predisposition to psychiatric disorders. Dev Psychopathol,1997; 9: 595-631.

[147] Schweitzer JB, Faber TL, Grafton ST, Tune LE, Hoffman JM, Kilts CD. Alterations in the functional anatomy of working memory in adult attention deficit hyperactivity disorder. Am J Psychiatry, 2000; 157(2): 278-280.

[148] Seidler FJ, Slotkin TA. Effects of acute hypoxia on neonatal rat brain: regionally selective, long-term alterations in catecholamine levels and turnover. Brain Res Bull, 1990; 24(2): 157-61. 
[149] Sesack SR, Deutch AY, Roth RH, Bunney BS. Topographical organization of the efferent projections of the medial prefrontal cortex in the rat: an anterograde tract-tracing study with phaseolus vulgaris leucoagglutinin. J Comp Neurol, 1989; 290 : 213-242.

[150] Shaw DS, Owens EB, Giovannelli J, Winslow EB. Infant and toddler pathways leading to early externalizing disorders. J Am Acad Child Adolesc Psychiat, 2001; 40(1): 36-43.

[151] Silberstein RB, Farrow M, Levy F, Pipingas A, Hay DA, Jarman FC. Functional brain electrical activity mapping in boys with attention-deficit/hyperactivity disorder. Arch Gen Psychiat, 1998; 55(12): 105-112.

[152] Simmel C, Brooks D, Barth RP, Hinshaw SP. Externalizing symptomatology among adoptive youth: prevalence and preadoption risk factors. J Abnorm Child Psychol, 2001; 29(1): 57-69.

[153] Smotherman WP. Mother-infant interaction and the modulation of pituitary-adrenal activity in rat pups after early stimulation. Dev Psychobiol, 1983; 16 : 169-176.

[154] Speiser Z, Amitzi-Sonder J, Gitter S, Cohen S. Behavioral differences in the developing rat following postnatal anoxia or postnatally injected AF-64A, a cholinergic neurotoxin. Behav Brain Res, 1988; 30: 89-94. 
[155] Speiser Z, Korczyn AD, Teplitzky I, Gitter S. Hyperactivity in rats following postnatal anoxia. Behav Brain Res, 1983; 7: 379-382.

[156] Spencer TJ, Biederman J, Wilens TE, Faraone SV. Overview and neurobiology of attention-deficit/hyperactivity disorder. J Clin Psychiat 2002; 63 Suppl 12: 3-9.

[157] Sprich-Buckminster S, Biederman J, Milberger S, Faraone SV, Lehman BK. Are perinatal complications relevant to the manifestation of ADD? Issues of comorbidity and familiality. J Am Acad Child Adolesc Psychiatry, 1993; 32(5): 1032-1037.

[158] Stefanatos GA, Wasserstein J. Attention deficit/hyperactivitiy disorder as a right hemisphere syndrome: Selective literature review and detailed neuropsychological case studies. Ann NY Acad Sci, 2001; 931: 172-195.

[159] Sullivan RM, Gratton A. Relationships between stress-induced increases in medial prefrontal cortical dopamine and plasma corticosterone levels in rats: role of cerebral laterality. Neuroscience, 1998; 83: 81-91.

[160] Sullivan RM, Gratton A. Lateralized effects of medial prefrontal cortex lesions on neuroendocrine and autonomic stress responses in rats. J Neurosci, 1999; 19: 2834-2840. 
[161] (a) Sullivan RM, Gratton A. Prefrontal cortical regulation of hypothalamic-pituitaryadrenal function in the rat and implications for psychopathology: side matters. Psychoneuroendocrinology, 2002; 27: 99-114.

[162] (b) Sullivan RM, Gratton A. Behavioral effects of excitotoxic lesions of ventral medial prefrontal cortex in the rat are hemisphere-dependent. Brain Res, 2002; 927: 69-79.

[163] Sullivan RM, Gratton A. Behavioral and neuroendocrine correlataes of hemispheric asymmetries in benzodiazepine receptor binding induced by postnatal handling in the rat. Brain \& Cogn, 2003; 51: 218-220.

[164] Sullivan RM, Szechtman H. Asymmetrical influence of mesocortical dopamine depletion on stress ulcer development and subcortical dopamine systems in rats: implications for psychopathology. Neuroscience, 1995; 65: 757-766.

[165] Swanson JM, Sergeant JA, Taylor E, Sonuga-Barke EJS, Jensen PS, Cantwell DP. Attention-deficit hyperactivity disorder and hyperkinetic disorder. The Lancet, 1998; 351: 429-433.

[166] Takagishi M, Chiba T. Efferent projections of the infralimbic (area 25) region of the medial prefrontal cortex in the rat: an anterograde tracer PHA-L study. Brain Res, 1991; 566(1-2): 26-39. 
[167] Terreberry RR, Neafsey EF. The rat medial frontal cortex projects directly to autonomic regions of the brainstem. Brain Res Bull, 1987; 19: 639-649.

[168] Thierry A.M, Tassin JP, Blanc G, Glowinski J. Selective activation of mesocortical DA systems by stress. Nature, 1976; 263: 242-243.

[169] Toft PB. Prenatal and perinatal striatal injury: a hypothetical cause of attention-deficithyperactivity disorder? Pediatr Neurol, 1999; 21(3): 602-610.

[170] Tranel D, Bechara A, Denburg NL. Asymmetric functional roles of right and left ventromedial prefrontal cortices in social conduct, decision-making, and emotional processing. Cortex, 2002; 38(4): 589-612.

[171] Van Eden CG, Buijs RM. Functional neuroanatomy of the prefrontal cortex: autonomic interactions. Prog Brain Res, 2000; 126: 49-62.

[172] Varlinskaya EI, Petrov ES, Robinson SR, Smotherman WP. Asymmetrical development of the dopamine system in the fetal rat as indicated by lateralized administration of SKF-38393 and SCH23390. Pharmacol Biochem Behav, 1995; 50: 359367. 
[173] Vezina P, Blanc G, Glowinski J, Tassin JP. Opposed behavioural outputs of increased dopamine transmission in prefrontocortical and subcortical areas: A role for the cortical D1 dopamine receptor. Eur J Neurosci, 1991; 3(10): 1001-1007.

[174] Voeller KK, Heilman KM. Attention deficit disorder in children: a neglect syndrome? Neurology, 1988; 38(5): 806-808.

[175] Weinberg WA, Harper CR. Vigilance and its disorders. Neurol Clin, 1993; 11(1): 5978.

[176] Wigger A, Neumann ID. Periodic maternal deprivation induces gender-dependent alterations in behavioral and neuroendocrine responses to emotional stress in adult rats. Physiol Behav, 1999; 66: 293-302.

[177] Williams GV, Goldman-Rakic PS. Modulation of memory fields by dopamine D1 receptors in prefrontal cortex. Nature, 1995; 376: 572-575.

[178] Zappitelli M, Pinto T, Grizenko N. Pre-, peri-, and postnatal trauma in subjects with attention-deficit hyperactivity disorder. Can J Psychiatry, 2001; 46(6): 542-548. 


\section{Figure Captions}

Figure 1: Schematic diagram demonstrating the relatively extended period of development of cortical dopamine afferents and concomitant risk factors for ADHD. It is proposed here that such a lengthy window of development is one reason why the mesocortical pathway may be vulnerable to early adverse experiences resulting in behavioral and neurochemical outcomes similar to some of those thought to occur in ADHD.

\section{$\underline{\text { Risk Factors for ADHD }}$}

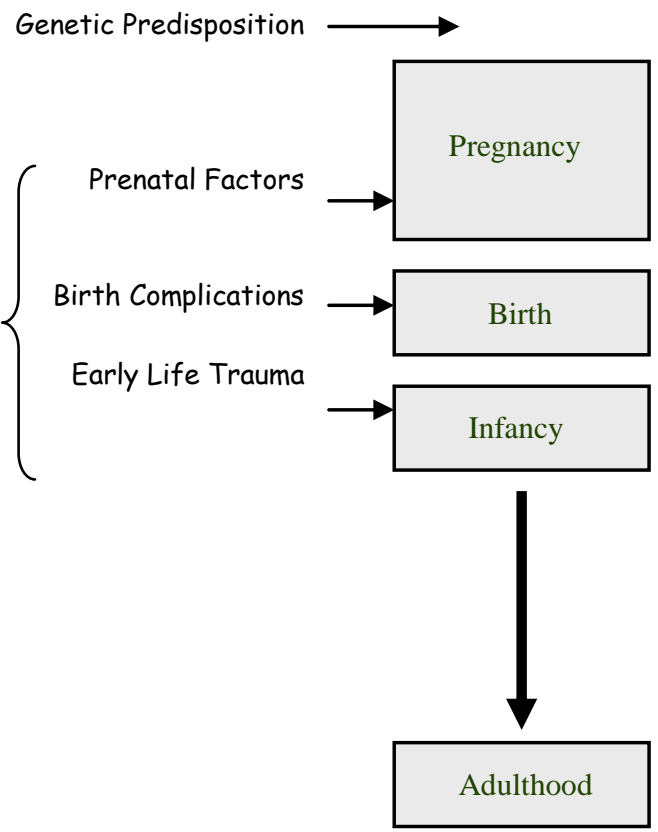

Development of Mesocortical

Dopamine Neurons

Final

Trimester-

Early

Childhood-

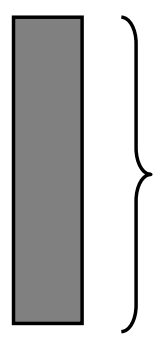

Begin Reaching Synaptic Targets

Adolescence-

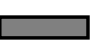

Achieve Adult Patterns 